Syifa Al-Qulub 4, 2 (Januari 2020): 106-114

Website: journal.uinsgd.ac.id/index.php/syifa-al-qulub

ISSN-25-8453 (online) dan ISSN-2540-8445 (cetak)

\title{
NILAI-NILAI KEBERMAKNAAN HIDUP MAMA SEMPUR (KH. TUBAGUS AHMAD BAKRI) DALAM NASKAH CEMPAKADILAGA
}

\author{
Ida Afidah \\ Universitas Islam Bandung \\ Email: idaafidah26@gmail.com \\ Titin Nurhayati Ma'mun \\ Universitas Padjajaran Bandung \\ Email: titin.mamun@unpad.ac.id \\ I. Syarief Hidayat \\ Universitas Padjajaran Bandung \\ Email: syahid.hd47@gmail.com \\ Elis Suryani \\ Universitas Padjajaran Bandung \\ Email: elis.suryani@gmail.com
}

\begin{abstract}
This study is aimed to find values of the meaning of life that written by Ajengan Mama Sempur in the Book of Campaka Dilaga. This study used a qualitative method with a literature study approach. The result of this study was found that the meaning of life of a Muslim can be found through the five values that exist in the five clauses and faidah's chapters, namely: First clause, discussing the urge to work / work for Muslims. The second clause, discussing the prohibition of doing business or doing work that is prohibited by Islam. The third clause, discussing the obligation to establish good relations with neighbors. The fourth clause, discussing the obligation of Muslims to serve and obey the legitimate government. The fifth clause, discussing the rules of ushul fiqh preventing harm is better than bringing benefit. The conclusion of this research is that the meaning of life can be found in the Sufistic values of Mama Sempur and her thoughts about the value of community life in accordance with the current conditions so as to give birth to good character.
\end{abstract}

Keywords:

Values; Meaning of Life; Mama Sempur; Campaka Dilaga.

\begin{abstract}
Abstrak
Penelitian ini bertujuan menemukan nilai-nilai makna hidup yang ditulis oleh Ajengan Mama Sempur dalam Kitab Campaka Dilaga. Penelitian ini menggunakan metode kualitatif dengan pendekatan studi literatur. Penelitian ini menghasilkan temuan bahwa makna hidup seorang muslim dapat ditemukan melalui panca nilai yang ada dalam lima Pasal dan bab faidah, tetapi yang menjadi tesis dalam kajian ini yaitu pada Pasal Pertama, membahas tentang dorongan berikhtiar/bekerja kepada umat Islam. Dan Pasal kedua, membahas tentang larangan menjalani bisnis atau melakukan pekerjaan yang dilarang oleh Agama Islam. Mama Sempur mengajarkan bahwa kebermaknaan hidup seseorang ada pada aktivitasnya (bekerja dan berkarya yang optimal), dan segala aktivitas dunia tersebut erat kaitannya dengan nilai spiritual ( harus berorientasi pada Allah) yang memiliki rejeki sehingga menjadi berkah, tidak ada dikhotomi antara aktivitas dunia dengan akhirat. Seorang ahli Psikologi Victor Emilie Frankl, dalam teori logoterapinya mengemukakan hal yang sama tentang kebermaknaan hidup manusia. Kesimpulan penelitian ini adalah kebermaknaan hidup seseorang dilihat dari kreatifitas yang menghasilkan karya sebaikmungkin. Makna hidup tersebut dapat ditemukan dalam nilai-nilai sufistik Mama Sempur dan pemikirannya, sehingga dapat melahirkan karakter manusia yang baik sesuai dengan kondisi yang dibutuhkan pada saat ini.
\end{abstract}

Kata Kunci:

Nilai-nilai; Makna Hidup; Mama Sempur; Campaka Dilaga 
Ida Afidah, Titin Nurhayati Ma'mun, Syarief Hidayat, Elis Suryani
Nilai Nilai Kebermaknaan Hidup Mama Sempur

(Kh. Tubagus Ahmad Bakri) Dalam Naskah

Cempakadilaga

DOI: http://dx.doi.org/10.15575/saq.v4i2.8337

Received: 2020-01-28; Accepted: 2020-01-28 ; Published: 2020-01-29

\section{A. PENDAhuluan}

Pemikiran Mama Sempur dalam Naskah Cempakadilaga; memaparkan hidup yang bertujuan dan penuh makna berorientasi pada pola hidup manusia yang benar, kembali pada ajaran agama sehingga hidup memiliki kebermaknaan. Makna hidup adalah hal-hal yang dianggap sangat penting dan berharga serta memberikan nilai khusus bagi seseorang, sehingga layak dijadikan tujuan dalam kehidupan (purpose of life). Makna dalam kehidupan dapat ditemukan dalam setiap keadaan, baik keadaan yang menyenangkan maupun tidak menyenangkan.

Naskah merupakan hasil tulisan tangan yang menyimpan berbagai ungkapan cipta, rasa, dan karsa manusia. Menjadi kekayaan intelektual pada masa lalu yang menjadi cerminan bagi generasi berikutnya yang sangat bermanfaat. Terutama dalam menghadapi tantangan hidup di jaman sekarang, yang tentunya sudah mengalami pergeseran nilai. Salah satu naskah keislaman, yaitu Cempakadilaga; Mertelakeun Perihal Wajib Usaha (Menerang Tentang Wajib Usaha/Kerja), karya KH. Tubagus Ahmad Bakri (dikenal dengan sebutan Mama Sempur keturunan Sunan Gunung Djati (Sultan Maulana Syarif Hidayatullah), termasuk naskah jamak (codex multus) yang ditulis dengan bahasa Sunda pegon. Beliau menuangkan pemikiran-pemikirannya tentang nilai kehidupan (makna hidup) yang sesuai dengan ajaran agama sehingga dapat melahirkan karakter manusia yang berkualitas. Naskah menjadi referensi dan pedoman masyarakat pada masa itu, bertujuan untuk mengajak dan menginspirasi mereka terhadap perubahan sosial dengan harapan agar dapat menjalani kehidupan yang lebih baik dan berkah.

Naskah Cempakadilaga terdiri dari lima pasal dan bab faidah, tetapi yang akan dibahas dalam kajian ini adalah pasal awal tentang "Wajib bekerja atau usaha kepada umat Islam". Pasa kedua, membahas tentang larangan menjalani bisnis atau melakukan pekerjaan yang dilarang oleh Agama Islam. Dalam Naskah Cempakadilaga, Mama Sempur menuangkan pemikiran- pemikirannya tentang nilai makna hidup (meaning in life) merupakan suatu motivasi, tujuan hidup, harapan yang harus dimiliki setiap individu, atau arti hidup bagi seseorang, maksudnya hidup itu untuk direspon dengan tindakan, melakukan sesuatu karena seseorang harus bertanggungjawab dalam hidupnya, bukan untuk dipertanyakan. Jadi kebermaknaan hidup adalah kualitas penghayatan individu terhadap seberapa besar dapat mengembangkan dan mengaktualisasikan potensi dan kapasitas yang dimilikinya serta seberapa jauh dapat mencapai tujuan dan memberi arti kepada kehidupannya. Victor Emilie Frankl seorang psikolog dari Vienna menguatkan pembahasan makna hidup dalam aliran psikoterapinya yang dikenal dengan logoterapi. Frankl menjelaskan bahwa makna akan ditemukan jika seseorang menarik dan mengaktifkan nilai spiritualitas pada individu tersebut. Ada tiga sumber makna yaitu 1) Creative Value (Nilai-nilai Kreatif), kegiatan berkarya, bekerja, mencipta serta melaksanakan tugas dan kewajiban sebaikbaiknya dengan penuh tanggung jawab; 2) Experiential Value (Nilai-nilai Penghayatan), yaitu keyakinan dan penghayatan akan nilainilai kebenaran, kebajikan, keindahan, keimanan dan keagamaan, serta cinta kasih; 3) Attitudinal Value (Nilai-nilai Bersikap), yaitu menerima dengan penuh ketabahan kesabaran dan keberanian segala bentuk penderitaan yang tidak mungkin dielakkan lagi.

Dalam naskah mama Sempur, sumber makna hidup didapatkan dari kaidah pertama yang mengungkapkan bahwa "arti bagi 
Ida Afidah, Titin Nurhayati Ma'mun, Syarief Hidayat,

Elis Suryani

keberadaan seseorang", dimaknai dengan bekerja, karena dengan bekerja seseorang dapat merealisasikan dirinya, memiliki karya bakti yang dilakukan, keyakinan terhadap harapan dan kebenaran serta penghayatanatas keindahan iman, cinta dan kasih, sesuai dengan ajaran agama sehingga dapat melahirkan karakter yang baik. Senada dengan penjelasan mama Sempur, Frankl menjelaskan sumber makna akan dicapai jika seseorang bekerka atau berkarya / creative values. Hal tersebut sebagai pijakan bagi masyarakat jaman sekarang yang sudah mengalami pergeseran nilai- nilai akhlak (karakter) karena adanya pengaruh budaya luar atau kondisi sosial politik tertentu.

Untuk mengembalikan orientasi umat dan perubahan sosial masyarakat, Mama Sempur menuangkan gagasan atau ide- idenya (melalui sebuah tulisan /naskah) yang disampaikan pada pengajian rutin setiap hari Selasa (waktu itu dikenal dengan istilah salasaan) dan setiap hari Kamis (istilah kamisan) menjadi referensi dan pedoman masyarakat pada masa itu. Pengajian rutin ini dihadiri oleh para santri dan masyarakat umum, dengan tujuan untuk mengajak dan menginspirasi mereka terhadap perubahan sosial dengan harapan agar dapat menjalani kehidupan yang lebih baik dan berkarakter sesuai dengan ajaran agama sehingga hidup lebih bermakna dan menjadi berkah. Kondisi tersebut di atas menjadi sebuah pelajaran yang dapat diambil hikmahnya untuk masa kini dan masa yang akan datang.

Pemikiran Mama Sempur dalam Naskah Cempakadilaga; memaparkan hidup yang bertujuan dan penuh makna berorientasi pada pola hidup manusia yang benar, kembali pada ajaran agama sehingga hidup memiliki kebermaknaan. Makna hidup adalah hal-hal yang dianggap sangat penting dan berharga serta memberikan nilai khusus bagi seseorang, sehingga layak dijadikan tujuan dalam kehidupan (purpose of life). Makna dalam kehidupan dapat ditemukan dalam setiap keadaan, baik keadaan yang menyenangkan maupun tidak menyenangkan.
Nilai Nilai Kebermaknaan Hidup Mama Sempur (Kh. Tubagus Ahmad Bakri) Dalam Naskah Cempakadilaga

Naskah merupakan hasil tulisan tangan yang menyimpan berbagai ungkapan cipta, rasa, dan karsa manusia. Menjadi kekayaan intelektual pada masa lalu yang menjadi cerminan bagi generasi berikutnya yang sangat bermanfaat. Terutama dalam menghadapi tantangan hidup di jaman sekarang, yang tentunya sudah mengalami pergeseran nilai. Salah satu naskah keislaman, yaitu Cempakadilaga; Mertelakeun Perihal Wajib Usaha (Menerang Tentang Wajib Usaha/Kerja), karya KH. Tubagus Ahmad Bakri (dikenal dengan sebutan Mama Sempur keturunan Sunan Gunung Djati (Sultan Maulana Syarif Hidayatullah), termasuk naskah jamak (codex multus) yang ditulis dengan bahasa Sunda pegon. Beliau menuangkan pemikiran-pemikirannya tentang nilai kehidupan (makna hidup) yang sesuai dengan ajaran agama sehingga dapat melahirkan karakter manusia yang berkualitas. Naskah menjadi referensi dan pedoman masyarakat pada masa itu, bertujuan untuk mengajak dan menginspirasi mereka terhadap perubahan sosial dengan harapan agar dapat menjalani kehidupan yang lebih baik dan berkah.

Naskah Cempakadilaga terdiri dari lima pasal dan bab faidah, tetapi yang akan dibahas dalam kajian ini adalah pasal awal tentang "Wajib bekerja atau usaha kepada umat Islam". Pasa kedua, membahas tentang larangan menjalani bisnis atau melakukan pekerjaan yang dilarang oleh Agama Islam. Dalam Naskah Cempakadilaga, Mama Sempur menuangkan pemikiran- pemikirannya tentang nilai makna hidup (meaning in life) merupakan suatu motivasi, tujuan hidup, harapan yang harus dimiliki setiap individu, atau arti hidup bagi seseorang, maksudnya hidup itu untuk direspon dengan tindakan, melakukan sesuatu karena seseorang harus bertanggungjawab dalam hidupnya, bukan untuk dipertanyakan. Jadi kebermaknaan hidup adalah kualitas penghayatan individu terhadap seberapa besar dapat mengembangkan dan mengaktualisasikan potensi dan kapasitas yang dimilikinya serta seberapa jauh dapat mencapai tujuan dan 
Ida Afidah, Titin Nurhayati Ma'mun, Syarief Hidayat, Elis Suryani

memberi arti kepada kehidupannya. Victor Emilie Frankl seorang psikolog dari Vienna menguatkan pembahasan makna hidup dalam aliran psikoterapinya yang dikenal dengan logoterapi. Frankl menjelaskan bahwa makna akan ditemukan jika seseorang menarik dan mengaktifkan nilai spiritualitas pada individu tersebut. Ada tiga sumber makna yaitu 1) Creative Value (Nilai-nilai Kreatif), kegiatan berkarya, bekerja, mencipta serta melaksanakan tugas dan kewajiban sebaikbaiknya dengan penuh tanggung jawab; 2) Experiential Value (Nilai-nilai Penghayatan), yaitu keyakinan dan penghayatan akan nilainilai kebenaran, kebajikan, keindahan, keimanan dan keagamaan, serta cinta kasih; 3) Attitudinal Value (Nilai-nilai Bersikap), yaitu menerima dengan penuh ketabahan kesabaran dan keberanian segala bentuk penderitaan yang tidak mungkin dielakkan lagi.

Dalam naskah mama Sempur, sumber makna hidup didapatkan dari kaidah pertama yang mengungkapkan bahwa "arti bagi keberadaan seseorang", dimaknai dengan bekerja, karena dengan bekerja seseorang dapat merealisasikan dirinya, memiliki karya bakti yang dilakukan, keyakinan terhadap harapan dan kebenaran serta penghayatanatas keindahan iman, cinta dan kasih, sesuai dengan ajaran agama sehingga dapat melahirkan karakter yang baik. Senada dengan penjelasan mama Sempur, Frankl menjelaskan sumber makna akan dicapai jika seseorang bekerka atau berkarya / creative values. Hal tersebut sebagai pijakan bagi masyarakat jaman sekarang yang sudah mengalami pergeseran nilai- nilai akhlak (karakter) karena adanya pengaruh budaya luar atau kondisi sosial politik tertentu.

Untuk mengembalikan orientasi umat dan perubahan sosial masyarakat, Mama Sempur menuangkan gagasan atau ide- idenya (melalui sebuah tulisan /naskah) yang disampaikan pada pengajian rutin setiap hari Selasa (waktu itu dikenal dengan istilah salasaan) dan setiap hari Kamis (istilah kamisan) menjadi referensi dan pedoman masyarakat pada masa itu. Pengajian rutin ini dihadiri oleh para santri dan masyarakat umum, dengan tujuan untuk
Nilai Nilai Kebermaknaan Hidup Mama Sempur (Kh. Tubagus Ahmad Bakri) Dalam Naskah Cempakadilaga

mengajak dan menginspirasi mereka terhadap perubahan sosial dengan harapan agar dapat menjalani kehidupan yang lebih baik dan berkarakter sesuai dengan ajaran agama sehingga hidup lebih bermakna dan menjadi berkah. Kondisi tersebut di atas menjadi sebuah pelajaran yang dapat diambil hikmahnya untuk masa kini dan masa yang akan datang.

\section{B. HASIL DAN PEMBAHASAN}

Nama Cempakadilaga diambil dari dua kata yaitu "cempaka" dan "dilaga". "Cempaka" adalah nama bunga yang berwarna putih bersih (latin;Michelia alba), memiliki keharuman yang mempesona dan membuat orang terpesona, dikenal sebagai bunga "lambang kepeimpinan", makna filosofisnya adalah memiliki sikap taggung jawab dan mampu mengayomi para pengikutnya dengan keteladanan yang ditunjukkannya. Sedangkan arti "dilaga" di-laga, adalah perang, berkelahi, pertunjukkan. Dalam bahasa Sunda memiliki arti yang hampir sama dengan di Banten yaitu perang, gaya, tingkah laku atau bergaya (misal; balaga). Dalam bahasa Irlandia "dilaga" mempunyai arti pengunjung tetap sebuah perkumpulan atau nama bagi aki laki yang berharap memiliki kebaikan sifat dan keunggulan karakter. Jadi Cempakadilaga memiliki makna manusia harus mempunyai jiwa bersih, suci (putih) dan harum seperti bunga yang direfleksikan dalam karakteristik yang berkualitas sebagi bentuk tanggungjawab hidupnya.

Adapun Isi pasal pertama dalam naskah Cempakadilaga perihal "bekerja", yang berbunyi: Pasal Awal "Menjelaskan perihal wajib usaha atau bekerja"

Hadist pertama, menjelaskan perintah bertani, adapun hadistnya berbunyi:

Uhrutsuu fainnal hartsa mubarokun waaktsiruu fihi minal jamaajimi.

Artinya: "Bercocok-tanam-lah wahai umat, karena dari usaha itu akan mendapatkan berkah, dan harus sebanyak-banyaknya, jangan hanya satu benih (satu warna)".

Hadist ini menegaskan: Pertama, bahwa pekerjaan yang paling utama adalah bercocok- 
Ida Afidah, Titin Nurhayati Ma'mun, Syarief Hidayat,

Elis Suryani

tanam, karena bercocok-tanam bermanfaat bagi seluruh makhluk. Setiap tumbuhan yang ditanam akan memberikan kehidupan kepada binatang seperti burung-burung, ulat, atau binatang lainnya dan menjadi berkah. Kedua, harus memanfaatkan lahan untuk bercocoktanam.. Oleh sebab itu, manusia yang bercocok-tanam akan mendapat ganjaran di akhirat.

Hadist kedua, menjelaskan tentang keharusan berusaha atau bekerja, adapun haditsnya berbuyi:

Innallaha ta'ala yuhibbu 'abdahul mu'minal faqiirol muta'affifa abal 'iyaali.

Artinya: "Sesungguhnya Allah Ta'ala menyukai umat yang mukmin, faqir, dan terjaga dari sifat meminta-minta. Jadi lebih baik bekerja daripada meminta-minta".

Hadist ketiga, berbunyi:

Innallaha ta'ala yuhibbu ayyaro 'abdahu ta'iban fi tolabil halali.

Artinya: "Allah ta'ala menyayangi umat yang lelah ketika mencari nafkah yang halal untuk keluarganya".

Sesungguhnya Allah Ta'ala memberikan ridho-Nya untuk manusia yang mencari nafkah yang halal, karena manusia yang memiliki harta banyak memiliki kebaikan. Kebaikan pertama yaitu memberikan manfaat untuk sesama dengan cara memberi dan dijauhkan dari manusia yang ingkar janji. Kedua, terhindar dari sifat meminta-minta. Menurut Syekh Rogib bekerja di dunia memilih satu jalan itu wajib, lalu wajib juga memilih jalan lain, karena jika manusia tidak beribadah namun harus menghilangkan kedarurotan hidupnya, yaitu memiliki harta agar menghilangkan ke-darurotannya. Perkara itu wajib meskipun tidak sempurna, namun manusia harus mendapatkan hasil yang sepadan, jangan hanya senang sendiri, karena itu prilaku dzalim. Barang siapa yang tidak bekerja maka tidak ber-prikemanusiaan, malahan lebih buruk dari binatang, tak ubahnya bangkai.

Hadist keempat, berbunyi:

Innallaha ta'ala yuhibbul mu'minul mubtadzilalladzi laa yubaalii maa yalbasu,
Nilai Nilai Kebermaknaan Hidup Mama Sempur (Kh. Tubagus Ahmad Bakri) Dalam Naskah Cempakadilaga

Artinya: "Sesungguhnya Gusti Allah menyayangi orang mukmin yang memakai pakaian penuh dengan tambalan: tidak peduli baju yang dipakai, asalkan halal dan menutupi aurat". Hadist ini juga menegaskan bahwa manusia yang tidak mau bekerja termasuk manusia yang buruk, termasuk manusia yang yang malas bekerja dan hanya ingin diberi oleh orang lain. Tetapi Syekh berpendapat dalam kitab 'Faidul Qodir Juz Tsani ( Hal. 23) yang bunyinya: Lakin syartuhu I'tiqoodurrizki minarrozaaqi laa minal kasabi,

Artinya: "Allah-lah yang memberi rizki, bukan pekerjaan. Bekerja jangan hanya mencari hasil berupa uang”.

Ka lima al-iyaamu biman yalzamuhum bihim minal ahli walaulaadzi wanahwihim

Artinya: "Niat yang baik adalah niat berusaha atau bekerja untuk memelihara kewajiban terhadap anak, istri, dan sesama".

Hadist kelima, berbunyi:

Innallaha yuhibbul mu'minal muhtarifa wayubgidu dussabah lala alladzi laa huwa fii 'amaliddunya walaa fii amalil akhiroti.

Artinya:" Sesungguhnya Allah Ta'ala menyukai orang mukmin: laki-laki maupun perempuan, yang mau bekerja mencari nafkah halal. Allah Ta'ala tidak menyukai orang yang malas bekerja dan mereka tidak mau beramal untuk bekal di akhirat".

Wajib kepada ihwan Islam untuk beramal shaleh. Adapun seruan Sayidina Umar bin Khatab: "Hai manusia yang menghabiskan umurmu di dunia dengan tidak beramal shaleh." Seyogyanya attajir yakni pedagang dan buruh harus memiliki niat yang baik ketika bekerja. Niat itu menyangkut lima perkara: pertama al-'afafu, badan terhindar dari makanan yang haram, kedua tahsilul kafaafi, yaitu memiliki niat bekerja untuk memberikan nafkah bagi diri sendiri, istri, dan anak, serta kerabat yang fakir. Ketiga kaffunnafsi an masalatinnaasi, yaitu mencegah hawa nafsu dan memiliki sifat malu untuk meminta-minta kepada orang lain. Keempat, attasyawufu illa maa biaidaihim, yaitu larangan mencuri, entah mencuri dari sesama muslim maupun bukan. Kelima, aliyaати biman yalzamuhum bihim minal ahli 
Ida Afidah, Titin Nurhayati Ma'mun, Syarief Hidayat, Elis Suryani

walaulaadzi wanahwihim, yaitu memiliki niat baik untuk memelihara kewajiban terhadap istri, anak, dan orang lain.

Ajaran Mama Sempur bahwa manusia sebagai khalifah di muka bumi ini diberi amanah untuk menjaga alam ini sehingga dengan 'bertani' atau bercocok tanam disebut sebagai usaha yang utama, karena selain memanfaatkan lahan tanah juga menjaga keharmonian alam dan bermanfaat buat keberlangsungan makhluk hidup lainnya (memenuhi kebutuhan makhluk lain), karena di sanalah terdapat nilai keberkahannya. Mengerjakannyapun harus dengan mengaitkan rasa keimanan kepada Yang Maha Kuasa. Perhitungan agama bukanlah perhitungan logika, tetapi hanya dapat dipahami dengan kecerdasan hati (iman) bukan kecerdasan akal. Manusia selalu berhitung logika, tidak yakin akan perhitungan Allah SWT., sehingga menjadi khawatir dan takut rugi. Beliau juga mengajarkan dalam bekerja (bertanam) harus kreatif dengan menanam beberapa jenis tanaman (tumpang sari).

Mama Sempur mencoba memberi solusi usaha dalam perspektif ajaran agama (spiritual) yang mengajarkan kebermaknaan hidup, diharapkan dapat mengantarkan masyarakat sekitarnya pada ketahanan ekonomi dengan kemandirian usaha sehingga dapat membangun dan memperkuat perekonomian rakyat.

Ajaran berikutnya tentang etos kerja, bahwa manusia yang baik dan terhormat adalah manusia yang mau bekerja atau usaha dan merasa malu atau merasa tidak punya harga diri apabila tergantung pada orang lain terlebih -meminta minta- bahkan dikatakan orang yang tidak mau bekerja (mencari nafkah) untuk keluarga adalah dzalim dan diibaratkan bangkai. Etos kerja sangat erat korelasinya dengan spiritual (tasawuf), bahkan di antara keduanya tidak ada dikhotomi. Sebagaimana landasan pikir reformis Imam al Ghazali tentang konsep Zuhd yang memadukan secara utuh antara syariat, thariqat dan hakikat bahwa penghayatan keagamaan harus melalui proses gradual dan kumulatif. Sufisme yang telah diperbaharui ini dikenal dengan neo
Nilai Nilai Kebermaknaan Hidup Mama Sempur (Kh. Tubagus Ahmad Bakri) Dalam Naskah Cempakadilaga

sufisme atau reformed sufism yang mengalihkan pengamatan pada rekontruksi sosio-moral masyarakat muslim yang berkarakter puritanis dan aktivis, dengan tujuan penekanan yang lebih inten pada penguatan iman sesuai prinsip akidah Islam dan penilaian terhadap kehidupan duniawi sama pentingnya dengan kehidupan ukhrawi. Konsekuensi dari sikap keberagamaan ini adalah terintegrasinya nilai kehidupan duniawi dengan nilai kehidupan ukhrawi. Dalam ajaran ini manusia harus memulai dengan taubat dan wara'(berusaha menjauhkan diri dari perbuatan dosa).

Dengan kebersihan hati dapat memandang yang sekilas tampak seperti bertolak belakang, karena spiritual dipahami sebagai jalan seorang hamba untuk mendekatkan dirinya kepada Tuhan- nya sehingga orientasinya ukhrawi. Sedangkan etos kerja dipahami sebagai aktivitas yang berorientasi duniawi. Menjadi bahwa spiritual dapat menyeimbangkan orientasi duniawi dan ukhrawi dalam diri seseorang sehingga dapat merasakan kenikmatan dalam membangun etos kerjanya. Ciri khas etos kerja adalah semangat kerja dan keyakinan seseorang untuk melakukan pekerjaan dengan sebaik baiknya dan penuh rasa tanggung jawab (akhlak dalam bekerja). Ciri etos kerja yang menonjol dari umat Islam adalah landasan keimanan, dia diminta untuk bekerja dengan cara yang baik, halal, dan bersungguh-sungguh, tetapi tidak melupakan aspek kepasrahan kepada Allah, "segala hasil yang dicapai dalam bekerja bukan semata-mata karena kepintaran dan kerja keras manusia, tetapi karena izin dan karunia serta rahmat dari Allah, sehingga tidak terlepas dari aspek syukur".

Banyak ayat yang mengkaitkan antara keimanan seseorang dengan amal (action), sedangkan keimanan itu adalah spiritual yang harus terus ditingkatkan melalui pendekatan kepada Allah (tasawuf). Allah SWT menjelaskan dalam surat Asy-Syams ayat 710, yang artinya: Demi jiwa serta penyempurnaan (ciptaan)nya, maka Allah mengilhamkan kepada jiwa itu (perilaku) kejahatan dan ketakwaannya. Sungguh 
Ida Afidah, Titin Nurhayati Ma'mun, Syarief Hidayat,

Elis Suryani

beruntung orang yang menyucikannya, dan sungguh merugi orang yang mengotorinya.

Adapun hubungan kecerdasan spiritual dengan etos kerja, menurut Zohar dan Marshall (2010) mengungkapkan ada beberapa faktor yang mempengaruhi kecerdasan spiritual yaitu:

a. Sel saraf otak Otak menjadi jembatan antara kehidupan bathin dan lahiriah.Ia mampu menjalankan semua ini karena bersifat kompleks, luwes, adaptif dan mampu mengorganisasikan diri. Menurut penelitian yang dilakukan pada era 1990-an dengan menggunakan WEG (Magneto-EncephaloGraphy) membuktikan bahwa osilasi sel saraf otak pada rentang $40 \mathrm{~Hz}$ merupakan basis bagi kecerdasan spiritual.

b. Titik Tuhan (God spot) Ada bagian dalam otak, yaitu lobus temporal yang meningkat ketika pengalaman religious atau spiritual berlangsung yang disebut sebagai titik Tuhan atau God Spot. Titik Tuhan memainkan peran biologis yang menentukan dalam pengalaman spiritual. Tentunya perlu adanya integrasi antara seluruh bagian otak, seluruh aspek dari dan seluruh segi kehidupan. Tasawuf identik dengan berdzikir, berdzikir dengan lidah, berdzikir dengan batin yang akhirnya berdzikir dengan perbuatannya. Berdzikir yang sampai tahap batin dapat mempengaruhi cara kerja otak manusia, dimana otak sebagai pusat perintah yang menggarakan seluruh tubuh (termasuk 'bekerja').

Di samping itu suatu pekerjaan atau usaha haruslah terjamin kehalalannya. Hal ini akan terbangun ekonomi yang sejahtera tanpa mengesampingkan nilai nilai akhlak/ moral. karena halal atau tidaknya yang kita dapatkan akan berpengaruh pada terbentuknya watak, tabiat, budi pekerti atau akhlak ( karakter) manusia itu sendiri.

Karakter yang berkualitas pada diri manusia adalah karakter yang memadukan antara jasmani dan rohani. Islam memberikan andil yang besar dalam mengajarkan pentingnya keseimbangan jasmani dan rohani pada diri manusia, sebagaimana dalam firman Allah: (Q.S. Shod: 71-72)
Nilai Nilai Kebermaknaan Hidup Mama Sempur (Kh. Tubagus Ahmad Bakri) Dalam Naskah Cempakadilaga

Artinya: (Ingatlah) ketika Tuhanmu berfirman kepada malaikat: "Sesungguhnya Aku akan menciptakan manusia dari tanah".. "Maka apabila telah Kusempurnakan kejadiannya dan Kutiupkan kepadanya roh (ciptaan) $\mathrm{Ku}$; maka hendaklah kamu tersungkur dengan bersujud kepadanya"

Menurut Syekh Muhammad Aqil dalam kitab Madhalun ila tasawuf al Islam, memahami ayat tersebut bahwa manusia memiliki dua kehidupan yaitu kehidupan materi dan ruhani. Apabila manusia tidak memperhatikan salah satunya, misalnya hanya memperhatikan kehidupan materinya (jasmani) maka kehidupan rohaninya akan sakit begitu juga sebaliknya, karena keduanya merupakan tabiat manusia. Oleh karena itu, tasawuf dalam makna hakikat adalah menghidupkan sesuatu yang dibutuhkan manusia, yaitu rohani, sebagaimana manusia membutuhkan materi untuk jasmani, agar kebahagiaan menjadi sempurna. Apabila manusia membutuhkan kehidupan rohani di kehidupan dunia, maka manusia membutuhkan tasawuf, karena tasawuf merupakan hakikat kehidupan rohani yang dapat melahirkan karakter manusia yang berkualitas. Dengan demikian hubungan manusia dengan tasawuf sangat erat, dan tidak dapat terpisahkan selama manusia hidup di bumi. Sebagaimana halnya ajaran Mama Sempur di atas yaitu menyeimbangkan antara kerja (usaha jasmani) dengan do'a kepada Allah SWT. (usaha rohani), sehingga setiap usaha atau kerja tidak berorientasi pada keuntungan nominal saja (profit oriented) tetapi nilai keberkahan nya pun harus diperhitungkan dan menjadi karakter dalam segala perbuatannya/kerjanya/usahanya.

Menurut Mama Sempur, menjalani hidup sesuai dengan ajaran agama, hidup menjadi penuh makna dalam berbagai aspek kehidupan di dunia. Kehidupan dimensi dunia itu tidak berdiri sendiri tetapi erat kaitannya dengan dimensi spiritual, sehingga kalau manusia dapat mengharmonikan keduanya bisa menjadi solusi untuk mengubah karakter dan kehidupan masyarakat menjadi lebih baik. 
Ida Afidah, Titin Nurhayati Ma'mun, Syarief Hidayat, Elis Suryani

Karena dimensi spiritual berupaya untuk mempertahankan keharmonisan atau keselarasan dengan dunia luar, berjuang untuk menjawab dan mendapatkan kekuatan ketika sedang menghadapi berbagai permasalahan. Dimensi spriritual ini dapat menumbuhkan kekuatan yang timbul di luar kekuatan manusia. Tetapi sebaliknya dampak yang terjadi jika seseorang terlalu mengandalkan ke -akuan- atau pekerjaan/ usahanya, maka dia akan menganggap semua yang terjadi merupakan akibat dari apa dia kerjakan/usahakan. Dia akan menutup semua celah yang menjadi sebab, selain pekerjaan/usahanya. Oleh karena itu pada saat pekerjaa/usaha tidak menjadi sebab keberhasilan (gagal), dia tidak memiliki harapan, jiwanya rapuh bahkan menghalalkan segala cara. Kesombongan manusia atas kekuatan dirinya, telah menolak kehadiran Tuhan untuk membantunya bahkan mengambil jalan yang bersebrangan dengan aturan Tuhan.

Spiritualitas (rohani) sebagai dimensi agama, memiliki konsep dua dimensi. Dimensi vertikal adalah hubungan dengan Tuhan Yang Maha Tinggi yang menunutun kehidupan seseorang, sedangkan dimensi horizontal adalah hubungan seseorang dengan diri sendiri, dengan orang lain dan lingkungannya, terdapat hubungan yang terus menerus antara dua dimensi tersebut.

Diakhir naskah Mama Sempur amalan amalan yang suluk serta do'a do'a yang harus didawamkan ( dikerjakan secara terus menerus) sebagai benteng agar manusia istiqamah dalam kebenaran, berada dalam (on the track) sesuai ajaran agama. Pemikiran Mama Sempur dalam Naskah Cempakadilaga; berorientasi pada pola hidup manusia yang benar, kembali pada ajaran agama sehingga hidup memiliki kebermaknaan. Tercermin dalam pandangannya terhadap Ilmu Pengetahuan, akal, bekerja dan usaha, bermasyarakat yang dikaitkan dengan nilai spiritual sebagai sebuah pembentukan karakter masyarakat yang sangat dibutuhkan masyarakat modern, terutama dalam menghadapi abad Industri (beyond 4.0),
Nilai Nilai Kebermaknaan Hidup Mama Sempur (Kh. Tubagus Ahmad Bakri) Dalam Naskah Cempakadilaga

berharap dapat mengambil nilai nilai positif atau hikmahnya sehingga terbentuk masyarakat yang lebih arif dalam menjalani kehidupannya.

\section{SIMPULAN}

Ajaran Mama Sempur tentang Kebermaknaan hidup manusia ada dalam aktivitasnya yang sebaik baiknya dan melakukan kewajiban dengan penuh tanggungjawab, hal tersebut akan terwujud apabila segala aktivitasnya dikaitkan dengan nilai spiritual (tasawuf) sehingga seseorang akan memiliki Creative Value, Experiential Value, Attitudinal Value. Manusiapun memiliki karakter yang baik, hidup menjadi berkah.

\section{DAFTAR PUSTAKA}

Aceh, Aboebakar, Pendidikan Sufi Sebuah Upaya Mendidik Akhlak Manusia, Solo, CV. Ramahani, n.d.

Ahmad, Mubarok, Jiwa dalam al-Qur"an, Jakarta: Paramadina, 2000

Atho, Nafisul., dkk, (2003), Hermeneutika Transedental: Dari Konfigurasi Filosofis Menuju Praksis Islamic Studies, Yogyakarta, IRCiSoD

Azra, Azyumardi, Kajian Naskah Islam Nusantara Minim, dalam http://www.republika.co.id/berita/duniaislam/islam-nusantara/10/07/19125424kajian-islam-nusantara-minim, diakses 3 Desember 2014

Baried, Siti Baroroh. Dkk, (1994). Pengantar Teori Filologi, Yogyakarta, UGM

Bastaman, H.D. (2007). Logoterapi (Psikologi untuk Menemukan Makna Hidup dan Meraih Hidup Bermakna). Jakarta: PT RajaGrafindo Persada.

Darsa, Undang A. (2013/2014). Kodikologi: Dinamika Identifikasi, Inventarisasi, dan Dokumentasi Tradisi Pernaskahan Sunda, Jatinangor, Fakultas Ilmu BudayaUniversitas Padjajaran

Djadjasudarma, Fatimah., dkk. (2016), Metodologi \& Strategi Penelitian Linguistik, Bandung, Fakultas Ilmu Budaya Universitas Padjajaran 
Ida Afidah, Titin Nurhayati Ma'mun, Syarief Hidayat,

Elis Suryani

Eagleton, Terry. (1983). Leterary Theory, Great Britain, Willing and Son Ltd

Ekadjati, Edi S. (2000). Direktori Edisi Naskah Nusantara, Jakarta, Masyarakat Pernaskahan Nusantara-Yayasan Obor Indonesia

Faruk. (2017), Pengantar Sosiologi Sastra dari Struktralisme Genetik sampai PostModernisme, Yogyakarta, Pustaka Pelajar

Fathurahman, Oma, .( 2015).Filologi Indonesia Teori dan Metode, Jakarta, Kencana

Fathurahman, Oman. (2000). "Filolofi dan Penelitian Teks-Teks Keagamaan" makalah disampaikan pada Workshop Pengembangan Agenda Riset, yang diselenggarakan oleh Local Project Implementing Unit (LPIU) UIN Syarif Hidayatullah Jakarta, di Wisma YPI, Ciawi Bogor,27 Maret

Ghanimi, Abu Wafa,(1974), Madkhal ila al Tasawuf al islam,Kiro:Daar al Tsaqafah

Ghozali, Al, Ihya Ulum al Din, Juz I, Dar Al Ma'arif: Bairut

Hermansoemantri, Emuch. (2011), Identifikasi Naskah, Bandung, Sastra Unpad Press

Ibn Arabi, (t.t). Al-Yawaqit wal Jawahir fi Bayan Aqa'id al-Akabir Juz 1, Beirut, Lubnan

Ikram, Achadiati (edt). (2004), Jati Diri Yang Terlupakan: Naskah-Naskah Palembang, Jakarta, Yayasan Naskah Nusantara (Manassa)

Kalabazi, Abu Bakar, (1343 H.) Ta'aruf li Mazdhab Ahli al Shufiyah, Kairo: Maktab al Zariyah

Kusuma, Okke. (2014), Semiotika dalam Analisis Karya Sastra, Depok, PT. Komodo Books Anggota IKAPI Lubis, Nabilah. (2007), Naskah,Teks, dan Metode Penelitian Filologi, Jakarta, Media Alo Indonesia

Littlejohn, Stephen. (2011), Teori Komunikasi: Edisi 9, Jakarta, Penerbit Salemba Humanika. Luxemburg, Jan Van, dkk,. (1992). Pengantar Ilmu Sastra, Jakarta, Gramedia Pustaka Utama
Nilai Nilai Kebermaknaan Hidup Mama Sempur (Kh. Tubagus Ahmad Bakri) Dalam Naskah Cempakadilaga

Manyambeang, Abd. Kadir. (1989). Pengantar Filologi. Ujung Pandang, Fakultas Sastra Universitas Hasanuddin

Muhadjir, Noeng. (2000), Metode Penelitian Kualitatif: Edisi IV, Yogyakarta, Rake Sarasin Nurizzati, (1997). Metode-Metode Penelitian Filologi. Padang: FBSS IKIP Padang

Permadi, Tedi. (t.t) Teks, Tekstologi, dan Kritik. Dan Penerapannya, Yogyakarta, Pustaka Pelajar

Robson, S.O., (1998). Principles of Indonesian Philology, Leiden: Foris Publication

Sangidu, Penelitian Sastra: Pendekatan, Teori, Metode, Teknik, dan Kiat, (Yogyakarta, Seksi Penerbitan Sastra Asia Barat Fakultas Ilmu Budaya UGM, 2005)

Siregar, Rivay. (1999), Tasawuf dari Sufisme Klasik ke Neo-Sufisme, Jakarta, PT. Raja Grafindo Persada

Sudibyo, (2015). Filologi, Sejarah, Metode, dan Paradigma, Yogyakarta, Jurusan Sastra Indonesia Fakultas Ilmu Budaya UGMManassa Cabang Yogyakarta.

Sumaryono, E. (1999), Hermeneutik: Sebuah Metode Filsafat, Yogyakarta, Penerbit Kanisius Anggota IKAPI.

Suryani, Elis. (2015), Teori, Metode, dan Kajian Filologi, Sumedang, UNPAD PRESS

Susanti, Dwi. (2012). Pengantar Teori Sastra, Yogyakarta, Caps

Teeuw, A. (2003). Sastera dan Ilmu Sastera, Jakarta, Pustaka Jaya

Tjandrasasmita,Uka. (2006), Kajian NaskahNaskah Klasik dan Penerapannya Bagi Kajian Sejarah Islam di Indonesia, Jakarta, Puslitbang Lektur Keagamaan Badan Litbang dan Diklat Departemen Agama RI.

Yunardi, Badri., dkk, (2015), Katalog Naskah Klasik Keagamaan, Puslitbang Lektur dan Khazanah Keagamaan, Badan Litbang dan Diklat Kementerian Agama RI. ..(2013), Sastra dan Ilmu Sastra, Bandung, PT. Dunia Pustaka Jaya. 